\title{
On the Age and Growth of the Labroid Fish Halichoeres poecilopterus from the Seto Naikai, Japan*1
}

\author{
Hiroaki Hashimoto, ${ }^{* 2}$ Kenji Gushima*2, and Shunpei Kakuda*2
}

(Received December 25, 1990)

\begin{abstract}
The age and growth of the labroid fish Halichoeres poecilopterus from the Seto Naikai were estimated by examining the scales based on the specimens collected from the Seto Naikai from 1981 to 1984 . With respect to the results of our study, one annulus of each scale is formed once a year in the hibernating period from January to April. This species spawns in early summer from late June to July, based on the temporal fluctuation in gonad index of the female. At the age of $1,2,3,4$ and 5 years old, the fishes are $61,86,106,124$ and $140 \mathrm{~mm}$ in standard length, respectively, as estimated by the marginal growth indices. The general growth of the fish is presented by the following formula described by BERTALANFFY:

$$
L_{b(\mathrm{~mm})}=234.8\left\{1-e^{-0.151(t-0.081)}\right\} .
$$

The length $(\mathrm{mm})$-weight $(\mathrm{g})$ relationship of this species is given by the formula, $W=4.886 \times$ $10^{-6} L^{3.280}$. Consequently the asymptotic weight is estimated as $291.6 \mathrm{~g}$.

The mean standard length of the immature yearlings collected in December, 1983 and 1984, were 42.4 and $42.3 \mathrm{~mm}$, respectively. The back-calculated standard lengths of yearling fishes in early summer are expected to be $44.7 \mathrm{~mm}$ in December. The back-calculated standard lengths of the yearling are almost equal to their actual standard length.
\end{abstract}

The labroid fish Halichoeres poecilopterus, Kyusen in Japanese, is a reef fish and commonly inhabits the coastal waters of Honshu, Kyushu and Shikoku, Japan. This species is commercially important in the Seto Naikai. According to the statistical annual report of Hiroshima Prefecture, in the central region of the Sea, its landing has ranged from 75 to $124 \mathrm{t}$ in the past 10 years. Then, one/two million young of $H$. poecilopterus are released anually around the coast of Hiroshima Prefecture.

It is well known that this species gets into the sandy sea bottom in order to hibernate in winter, ${ }^{1)}$ and all females over about $14 \mathrm{~cm}$ in standard length change their sex into male in the Seto Naikai. ${ }^{2)}$ There have been studies of this species concerning sex-change, ecological and physiological characteristics. ${ }^{1-11)}$ However, the age and growth of this species has never been studied.

In the present study we intended to estimate the age and the growth of $H$. poecilopterus from the Seto Naikai by analysing the annual rings shown on the scales. But it was not possible to distinguish the difference in growth between males and females because of the sex-change. So for the present paper the age and growth of this species were determined without distinguishing between males and females.

\section{Materials and Methods}

We examined 741 adult specimens of $H$. poecilopterus to examine the scales and 195 immature yearlings to check the relationship between the back-calculated standard length and the actual length at $t$ years old. All these adult fishes were collected monthly from May 1981 to December 1984 in the central region of the Seto Naikai, except for four months from January to April, when they hibernate. The immature yearlings were collected in December, 1983 and 1984 in the coastal region of the Hakama-shima Is., off Fukuyama, Hiroshima Prefecture.

The specimens were measured and weighed in the laboratory, and several scales removed from the left side of the body, just behind the base of the pectoral fin below the lateral line. The scales removed were immersed in a $5 \% \mathrm{KOH}$

*1 This work was partly presented orally at the Annual Meeting of Japan. Soc. Sci. Fish. held at Tokyo in April, 1985.

*2 Faculty of Applied Biological Science, Hiroshima University, Higashi-Hiroshima 724, Japan (桥本博明， 具島健二, 角田俊平：広泉大学生物生産学部). 


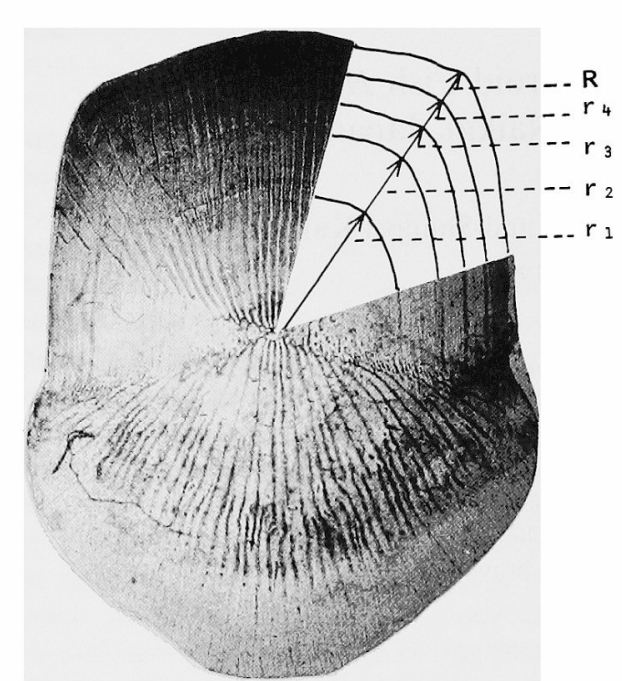

Fig. 1. A scale of $H$. poecilopterus and a example of showing the measuring axis, scale radius $(R)$ and annulus radii $\left(r_{n}\right)$. Each numeral denotes the age.

solution to remove the mucus and cleaned with water. The scales cleaned were mounted between two pieces of slide glass and observed by a projector of $20 \mathrm{X}$ magnification.

The annuli are shown at the anterior portion of the scale embedded in the sheath. An annulus on the scale is definable as a zone which comprises irregularly arranged ridges in the anterior sector and intercepts the adjacent inner ridges in the right and left lateral sectors as shown in Fig. 1.

The scales were measured along the anterolateral axis. The scale radius $(R)$ is represented by the distance between the focus and the anterolateral angles, and the annulus radius $\left(r_{n}\right)$ is the distance between the focus and the antero-lateral annulus (Fig. 1). For each fish specimen, one normal scale with a focus was picked and its scale radius and annulus radii measured.

\section{Results and Discussion}

The relationship between the scale radius and the annulus radii was examined for the scales taken from the various body parts of the specimen, $128 \mathrm{~mm}$ in standard length with four annuli in each scale. As the result of this examination, the relationship between the scale radius and the radii of the definite annuli in the scales from this specimen can be expressed by four regression lines, as shown in Fig. 2.

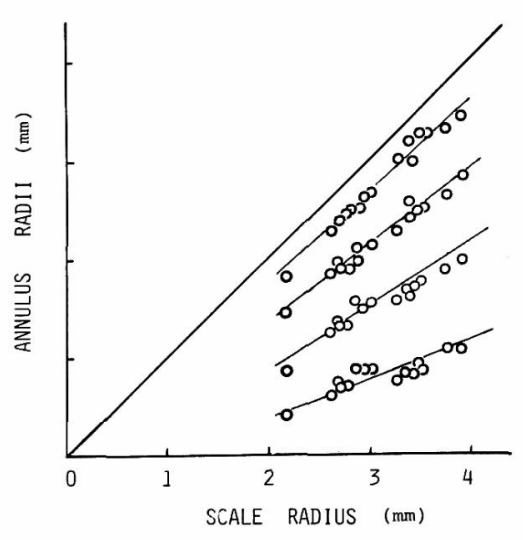

Fig. 2. Relationship between scale radius and annulus radii in the scale taken from various body parts of the specimen, $128 \mathrm{~mm}$ in standard length.

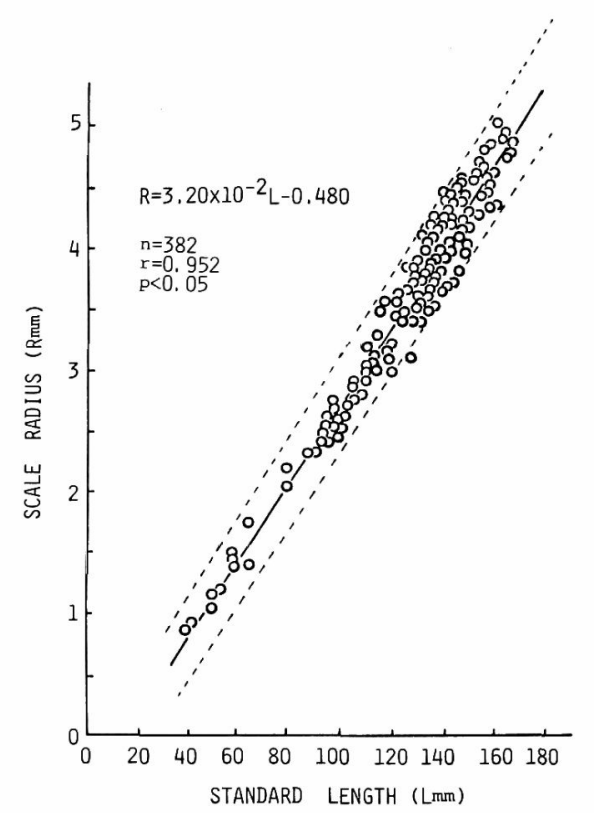

Fig. 3. Relationship between standard length and scale radius.

The relationship between the standard length $(L: \mathrm{mm})$ and the scale radius $(R: \mathrm{mm})$ of the scales taken from the fixed body part is linear, as shown in Fig. 3, and is expressed as follows:

$$
R=3.20 \times 10^{-2} L-0.480
$$

The annulus radii vary according to the scale radius (Fig. 2). Even if the specimens have almost the same standard length, the scale radii of their scales removed from a fixed body part 
Table 1. Standard annulus radius in each ring group and their mean values, and back-calculated standard length at the time of the annual ring formation for each ring group

\begin{tabular}{|c|c|c|c|c|c|c|c|c|c|}
\hline \multirow{2}{*}{ Ring group } & \multirow{2}{*}{$\begin{array}{l}\text { No. of } \\
\text { specimens }\end{array}$} & & & \multicolumn{6}{|c|}{ Means of standard annulus radius in $\mathrm{mm}$} \\
\hline & & & & $r_{1}$ & $r_{2}$ & $r_{3}$ & $r_{4}$ & $r_{5}$ & $r_{B}$ \\
\hline 1 & 159 & & & 0.94 & & & & & \\
\hline 2 & 143 & & & 0.95 & 1.89 & & & & \\
\hline 3 & 170 & & & 0.96 & 1.87 & 2.59 & & & \\
\hline 4 & 157 & & & 0.95 & 1.87 & 2.56 & 3.20 & & \\
\hline 5 & 71 & & & 0.95 & 1.85 & 2.59 & 3.18 & 3.74 & \\
\hline 6 & 41 & & & 0.94 & 1.87 & 2.56 & 3.21 & 3.73 & 4.22 \\
\hline \multirow{4}{*}{$\begin{array}{l}\text { Standard } \\
\text { annulus } \\
\text { radii in } \\
\text { each ring }\end{array}$} & & \multicolumn{2}{|l|}{ Mean } & 095 & 1.87 & 2.58 & 3.19 & 3.74 & 4.22 \\
\hline & & \multicolumn{2}{|l|}{$\mathrm{SD}$} & 0.14 & 0.21 & 0.21 & 0.22 & 0.20 & 0.22 \\
\hline & & \multirow{2}{*}{ Range } & $\min$. & 0.60 & 1.30 & 2.11 & 2.63 & 3.26 & 3.76 \\
\hline & & & $\max$ & 1.37 & 2.35 & 3.09 & 3.76 & 4.22 & 4.67 \\
\hline \multicolumn{4}{|c|}{ Total number of } & 741 & 582 & 439 & 269 & 112 & 41 \\
\hline \multicolumn{4}{|c|}{$\begin{array}{l}\text { Back-caluculated standard length in mm at } \\
\text { the time of the annual ring formation }\end{array}$} & 45 & 73 & 96 & 115 & 132 & 147 \\
\hline
\end{tabular}

include variations and show some variance (Fig. 3). Consequently, to define the variance in each fish, it is necessary to compute the value of the scale radius for the standard length by applying the empirical formula (1), and this scale radius is termed the "standard sacle radius" $(\tilde{R})$. By multiplying $\widetilde{R}$ with the ratio of the annulus radius $\left(r_{n}\right)$ to the scale radius $(R)$ in each sample specimen, the "standard annulus radius" $\left(\tilde{r}_{n}\right)$ can be given. The mean value of the standard annulus radius and back-calculated standard length at the time of the annual ring formation for each ring group by the formula (1) are shown in Table 1 . The scale size grows in proportion to the growth of the fish. The monthly changes of the marginal growth index (MGI), $\left(R-r_{n}\right) /\left(r_{n}-r_{n-1}\right)$, which express the relative growth patterns of the scale in a year, are shown in Fig. 4. This index, which

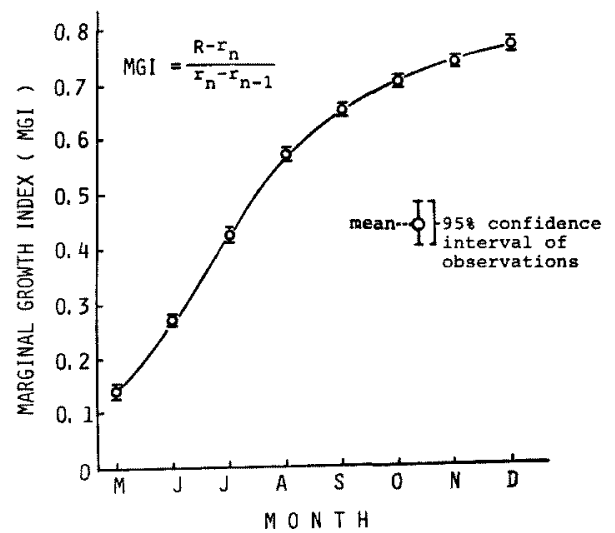

Fig. 4. Monthly change of marginal growth index (MGI). The growth curve was adjusted visually.

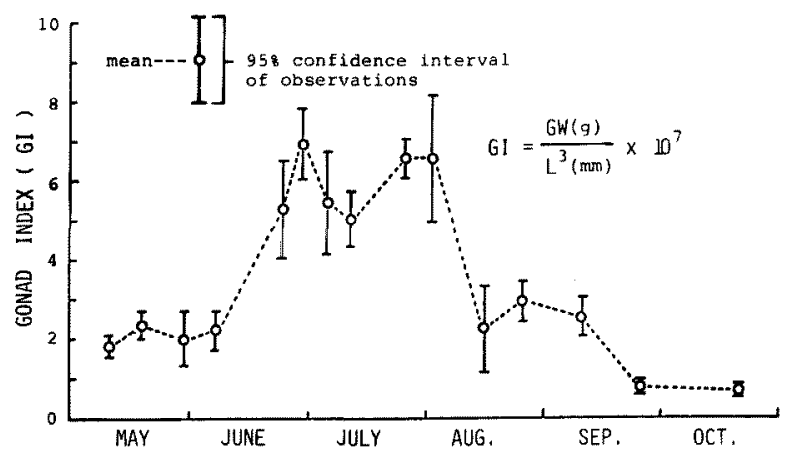

Fig. 5. Temporal fluctuation in the gonad index (GI) of the female. 
Table 2. The standard length $\left(L_{t}\right)$ of $t$-year-old fish calculated by combining the back-calculated standard length of $t$ ring group shown in Table 1 and the monthly marginal growth index shown in Fig. 4

\begin{tabular}{crrccc}
\hline Age & 1 & 2 & 3 & 4 & 5 \\
\hline$L_{t}(\mathrm{~mm})$ & 61 & 86 & 106 & 124 & 140 \\
\hline
\end{tabular}

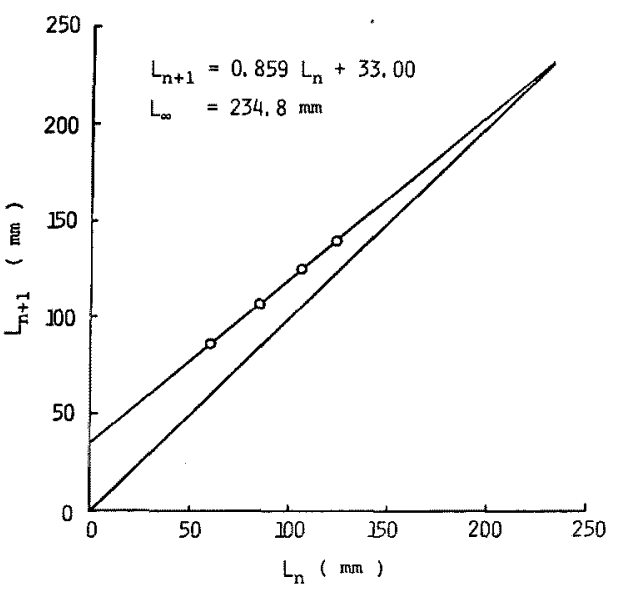

Fig. 6. WALFORD's growth transformation of standard length. is given as the mean value for each month, shows the minimum value in May, increases gradually from June to December and attains the maximum value in December.

In the central part of the Seto Naikai, this species goes into the sand bed to hibernate from mid December to early January when the water temperature falls below $15^{\circ} \mathrm{C}$ and appears at the beginning of May when the water temperature rises over $15^{\circ} \mathrm{C}$, based on our observations. Judging from the monthly variational pattern of MGI (Fig. 4) and the observational result noted above, it is concluded that an annual ring is formed from January to April. Moreover, Fig. 4 shows clearly that this fish grows rapidly between May and September.

The gonad index (gonad weight $\times 10^{7}$ )/(cube of standard length) is often used to ascertain the maturity of the fish. The seasonal fluctuation of the gonad index of the female is shown in Fig. 5. This figure shows that this species spawns from late June to July. Accordingly, it is inferred that the first annual ring forms itself about a half-year after hatching.

The standard length $\left(L_{t}\right)$ of t-years old fish is shown in Table 2 . This was calculated by combin-

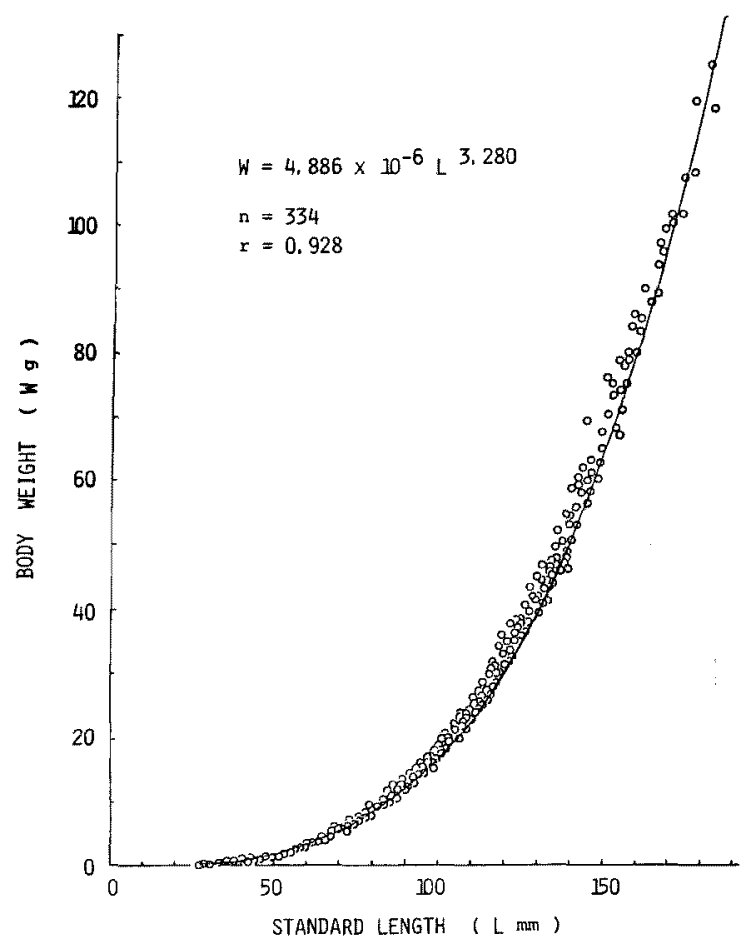

Fig. 7. Length-weight relationship of H. poeciloptertus. 


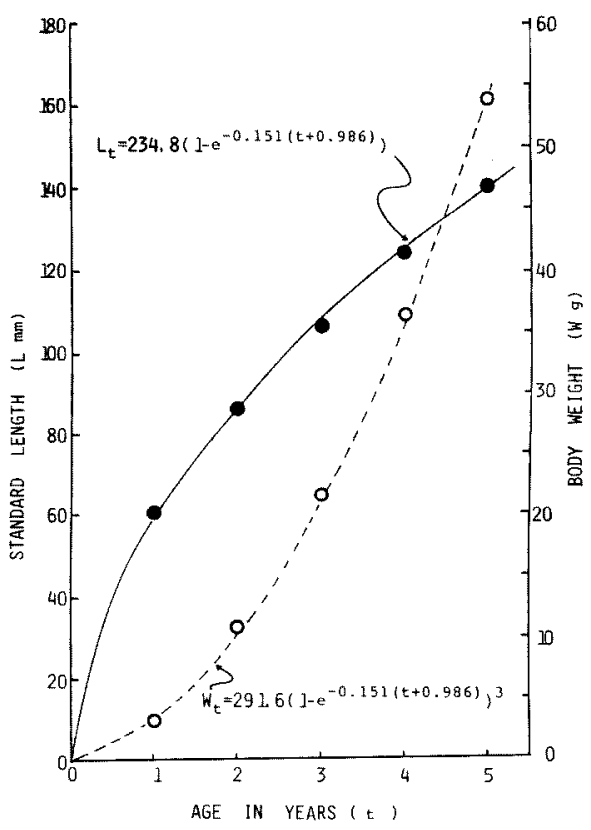

Fig. 8. Growth curves in the standard length and body weight of $H$. poecilopterus. The solid circle indicates the mean standard length in each age group and the open circle indicates the body weight computed from the mean standard length by the equation of length-weight relationship shown in Fig. 7.

ing the back-calculated standard length of $t$ ringgroup shown in Table 1 and the MGI in Fig. 4. The standard length of $L_{t+1}$ is plotted for $L_{t}$ as shownin Fig. 6. The phase of this WaLFord's diagram $^{22)}$ can be represented as a straight line expressed by the following formula:

$$
L_{n+1}=0.859 L_{n}+33.00
$$

These results indicate that the data shown in Fig. 6 can be fitted into vON BerTalanfFy's model. ${ }^{13)}$ Thus, putting $t=0$ at the hatching time, the growth curve of this species is given by the following formula:

$$
L_{t}=234.8\left\{1-e^{-0.151(t+0.880)}\right\}
$$

in which, $L_{t}$ is the standard length in mm at $t$ years after hatching.

The length-weight relationship of $H$. poecilopterus is shown in Fig. 7. The regression equation is denoted as follows:

$$
W=4.886 \times 10^{-8} L^{3.280}
$$

where $W$ stands for the estimated round weight in

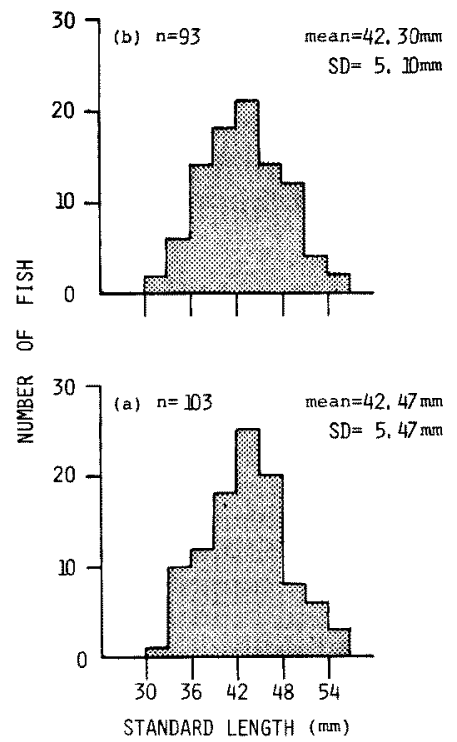

Fig. 9. Length frequency of the immature yearlings collected in December, 1983 (a) and ' 84 (b). SD: standard deviation.

$\mathrm{g}$ and $L$ for the standard length in $\mathrm{mm}$. By using the equations (3) and (4), the growth in body weight can be expressed as follows:

$$
W t=291.6\left\{1-e^{-181(t+0.888)}\right\}^{3}
$$

Therefore, the growth curves of standard length and body weight in $H$. poecilopterus from the Seto Naikai are shown in Fig. 8.

Each length frequency of the immature yearlings collected in 1983 and 1984 shows an mono-modal distribution (Fig. 9). The mean standard length for 1983 is $42.45 \mathrm{~mm}$ and its standard deviation $5.47 \mathrm{~mm}$. Those of 1984-yearlings are $42.30 \mathrm{~mm}$ and $5.10 \mathrm{~mm}$, respectively. These yearlings were captured in December. As noted above, the annual ring on the scale is formed from January to April. The back-calculated standard length of yearlings hatching out in late June to July is expected to reach $44.7 \mathrm{~mm}$ in December of the year. Accordingly, the estimated standard length corresponds nearly with the actual standard length:

\section{Acknowlegments}

We would like to thank Dr. Peter Goldsbury, the Associate Professor in the Faculty of Integrated Arts and Sciences, Hiroshima University, for his checking the manuscript. We wish to thank 
Messrs. Tetsuo Morino and Yousuke Tsushima for helping to measure the specimens and their scales, and Mr. Yukio Fukui for helping to collect immature yearlings. They were students at the Fisheries Biology Laboratory in the Faculty of Applied Biological Science, Hiroshima University.

\section{References}

1) Y. Kinosita: Zool. Mag., 47, 795-799 (1935).

2) Y. Fukui, K. Gushima, S. Kakuda, and H. Hashimoto: Japan. I. Ichthyol., 37, 395-401 (1991).

3) Y. Kinosita: Jour. Sci. Hiroshima Univ. Ser. B. Div. 1, 3, 65-76 (1934).

4) Y. Kinoshita: Plants and Animals, 3, 1275-1282
(1935).

5) Y. Kinoshita: Jour. Sci. Hiroshima Univ. Ser. B. Div. 1, 4, 1-14 (1935).

6) Y. Kinoshita: Plants and Animals, 4, 1027-1030 (1936).

7) Y. K. Okada: Proc. Japan Acd., 38, 508-513 (1962).

8) Y. K. Okada: Proc. Japan Acd., 40, 533-535 (1964).

9) Y. K. Okada: Proc. Japan Acd., 40, 541-544 (1964).

10) H. Nakazono: Fish. Res. Lab. Kyushu Univ., 4, 1-64 (1979).

11) G. Kawamura and T. Tamura: Nippon Suisan Gakkaishi, 39, 715-726 (1973).

12) L. A. Walford: Bio. Bull., 90, 141-147 (1946).

13) L. von Bertalanffy: Human Bio., 10, 181-213 (1938). 